\title{
Testing the Altresyn Product for Oestrus Synchronization in Gilts
}

\author{
Liviu BOGDAN ${ }^{1}$, Sanda ANDREI ${ }^{1}$, Adrian MACRI ${ }^{1}$, Ileana BOGDAN ${ }^{2}$, Mihai BORZAN ${ }^{1}$, Sidonia BOGDAN ${ }^{1}$, \\ Anamaria BLAGA PETREAN ${ }^{1 *}$ \\ ${ }^{1}$ Faculty of Veterinary Medicine, University of Agricultural Sciences and Veterinary Medicine, Mănăştur \\ Street, no.3/5, Cluj-Napoca, Romania \\ ${ }^{2}$ Faculty of Agriculture, University of Agricultural Sciences and Veterinary Medicine, Mănăştur Street, \\ no.3/5, Cluj-Napoca, Romania \\ *corresponding author: anamariapetrean@yahoo.com
}

Bulletin UASVM Veterinary Medicine 74(1) / 2017,

Print ISSN 1843-5270; Electronic ISSN 1843-5378

DOI:10.15835/buasvmcn-vm: 12595

\begin{abstract}
The aim of this study was to evaluate the effect of Altresyn ${ }^{\circledR}$ product (progesterone-based product) as a method for synchronization of oestrus in gilts. The gilts were divided into three experimental groups. The synthetic progesterone Altrenogest was fed daily to 39 gilts at $20 \mathrm{mg} /$ gilts for 18 days. In case of the first group ( $\mathrm{n}=11$ gilts) the treatment was performed using only Altresyn product. In group II ( $\mathrm{n}=13$ gilts) was administered the prostaglandin hormone (Prosolvin), $0.75 \mathrm{mg}$ at 24 hours after Altrenogest treatment suppression. Group III ( $\mathrm{n}=15$ gilts) received one injections of PMSG hormone (Folligon), 500 IU/animal. Gilts were checked for oestrus twice daily and were artificially inseminated. All gilts expressed signs of oestrus between 3 and 6 days after withdrawal of Altrenogest. At the groups that were administered prostaglandin and PMSG there was a shorter duration of oestrus (group III - 26.66 hours, group II - 27.07 hours) compared to group I (28.54 hours). In this study, pregnancy rate ranged from $45.45 \%$ (group I) and $93.33 \%$ (group III), while in group II the value slightly exceeded 50\% (53.84\%). In group I, the mean litter size was 11.6 piglets, in group II the mean value of farrowed piglets was 13.28 and 15 piglets in group III. Regarding the average number of weaned piglets in group I was 8.8, 12 in group II, while for the third group was 13.14. Altrenogest, the active ingredient in Altresyn ${ }^{\circledR}$ is effective for regulating the oestrus of gilts in commercial pig farms.
\end{abstract}

Keywords: Altresyn, gilts, oestrus, synchronization.

\section{INTRODUCTION}

In today's competitive pork industry, it is essential that producers achieve a high level of reproductive efficiency. Low performance in the breeding systems can lead to complications in the production calendar. The hormonal treatment strategies are tools that producers can use to help in that regard (Coffey et al., 1997).

The administration of progestogens has confirmed to be highly effective in synchronization of oestrus in cyclic sows and gilts (Gerrits and Johnson, 1965; Polge et al., 1968; Dimitrov et al.,
2010). The orally active progestogen "altrenogest" is effective for producing synchronization of oestrus cycles in swine and would potentially facilitate synchronization of cycling sows and gilts. The oestrus response can be improved by PGF2 $\alpha$ and gonadotrophin treatment at the end of altrenogest feeding (Estill, 2000).

The aim of this study was to evaluate the effect of Altresyn ${ }^{\circledR}$ product (progesterone-based product) as a method for synchronization of oestrus in gilts. 


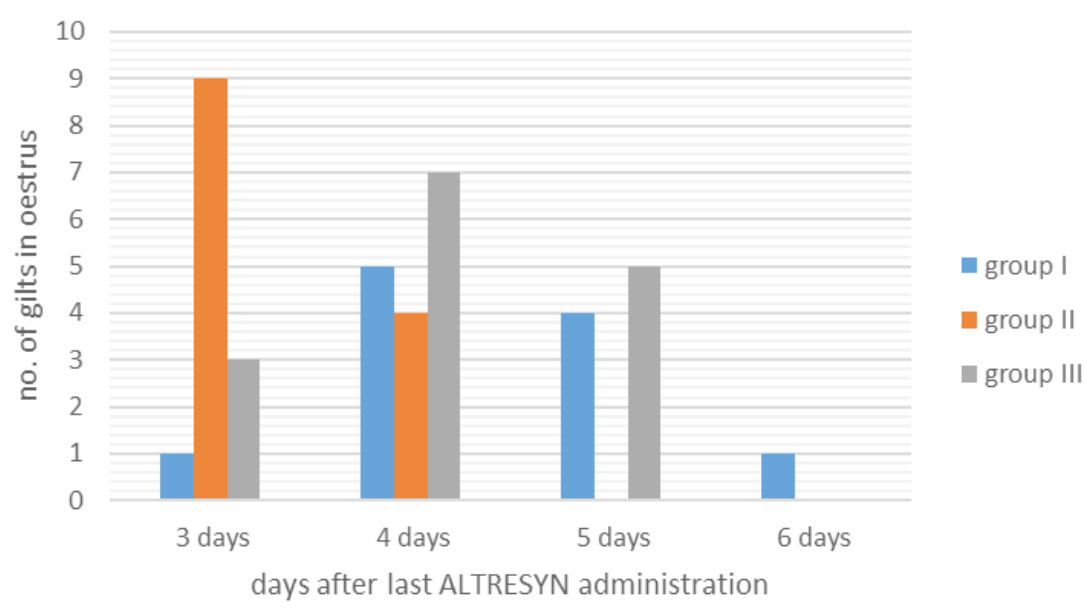

Fig. 1 - Distribution of gilts in oestrus after hormonal treatment

\section{MATERIAL AND METHODS}

The study was carried out between June 2013 - May 2014 in a private unit in Cluj County, and involved 39 gilts, aged between 210-220 days.

The gilts were divided into three experimental groups. In all groups oestrus synchronization was performed with the commercial product Altresyn administered orally in a daily dose of 20 mg altrenogest/animal/day, which corresponds to $5 \mathrm{ml}$ Altresyn/animal/day, for 18 consecutive days. In case of the first group ( $\mathrm{n}=11$ gilts) the treatment was performed using only Altresyn product. In group II ( $\mathrm{n}=13$ gilts) 24 hours after cessation of progesterone treatment prostaglandin hormone (Prosolvin) was administered at a dose of $0.75 \mathrm{mg}$. Group III ( $\mathrm{n}=15$ gilts) received one injections of PMSG hormone (Folligon) at the dose of $500 \mathrm{IU} /$ animal. Animals were separated and individually treated. It should be mentioned that it was given the right dose for each animal, because underdosing may lead to cystic follicles (Davis et al., 1979; Kraeling et al., 1981).

The animals were monitored until first clinical signs of oestrus were detected. Oestrus was detected with boar exposure twice a day after cessation of hormonal treatment. Two Landrace boars with good fertilizing capacity were used. Semen was collected twice per week and volume, color and motility were evaluated. The semen was diluted in Merck III extender (Minitube), packaged in $100 \mathrm{ml}$ bottles with $4.0 \times 10^{9}$ spermatozoa. Diluted semen was storaged at $18{ }^{\circ} \mathrm{C}$.

Gilts received first artificial insemination (AI) 12 hours after oestrus was detected and second
AI 21 days. Pregnancy rate was determinated at 30 days after insemination by using a portable ultrasound. All pregnant gilts were kept under observation and, a week before parturition, were moved in individual boxes.

The following parameters were investigated: interval of oestrus onset, oestrus duration, pregnancy rate, total piglets born per litter, weaned piglets.

Statistical analysis was performed with operating system Windows 2007 - Descriptive statistics.

\section{RESULTS AND DISCUSSIONS}

Using a combined hormonal treatment (altrenogest with prostaglandin or FSH respectively) the interval between the last treatment and oestrus could be reduced. The best results were obtained in group II: $100 \%$ of the animals presented signs of oestrus on days 3 to 4 after the hormonal treatment, with an average of $3.30 \pm 0.48$ days. In group I and III, following withdrawal of altrenogest, $81.81 \%$ respectively $79.99 \%$ of the gilts displayed oestrus on days 4 and 5, with an average withdrawal-to-oestrus interval of $4.45 \pm 0.82$ and $4.13 \pm 0.60$ days (Fig. 1). Similar results were recorded for gilts treated with the same dose of altrenogest (Davis et al., 1976; Knight et al., 1976; Webel and Scheid, 1980; Dimitrov et al., 2010).

At the groups that were administered prostaglandin and PMSG there was a shorter duration of oestrus (group III - 26.66 \pm 2.46 hours, group II $-27.07 \pm 2.39$ hours) compared to group I 
Tab. 1 Descriptive analysis of the farrowed and weaned piglets

\begin{tabular}{cccc}
\hline Parameters & group I & group II & group III \\
\hline Mean & 11.5454545 & 13.30769 & 15 \\
\hline Standard Error & 0.31228298 & 0.327864 & 0.292770022 \\
\hline Median & 12 & 13 & 15 \\
\hline Mode & 12 & 13 & 15 \\
\hline Standard Deviation & 1.03572548 & 1.182132 & 1.133893419 \\
\hline Sample Variance & 1.07272727 & 1.397436 & 1.285714286 \\
\hline Kurtosis & -0.8532031 & -0.28636 & -0.179487179 \\
\hline Skewness & -0.1472807 & -0.34924 & 0.339198886 \\
\hline Range & 3 & 4 & 4 \\
\hline Minimum & 10 & 11 & 13 \\
\hline Maximum & 13 & 15 & 17 \\
\hline Sum & 127 & 173 & 15 \\
\hline Count & 11 & 13 & 0.627929246 \\
\hline Confidence Level (95.0\%) & 0.69580985 & 0.714355 &
\end{tabular}

(28.54 \pm 2.01 hours). The percentage of oestrus return was $63.63 \%$ (7 gilts) in group I, $61.54 \%$ (8 gilts) in group II and for group III at a number of 5 gilts (33.33\%) showed signs of oestrus after the first cycle. In this study, pregnancy rate ranged from $45.45 \%$ (group I) and $93.33 \%$ (group III), while in group II the value slightly exceeded $50 \%$ (53.84\%). Similar values (51.85 to $90.48 \%$ ) were reported by Dimitrov et al., 2010.

In our study, the mean values of farrowed and weaned piglets, regardless of treatment, was in accordance with other authors (Dimitrov et al., 2010; Boyer and Almond, 2014), and indicates that acceptable farrowing response after synchronization with altrenogest should be achieved consistently (Tab. 1). Dimitrov et al., 2010 , found that total litter size ranged between $7.88 \pm 4.72$ and 14.42 \pm 2.36 , while Boyer and Almond, 2014, have reported that the mean value for the piglets born alive was between $10.06 \pm 0.08$ and $10.33 \pm 0.06$. Same authors revealed a mean value of weaned piglets between $9.78 \pm 0.08$ $10.31 \pm 0.03$.

\section{CONCLUSIONS}

Results showed that Altresyn product, alone or in combination with other hormones, when fed daily for 18 days at $20 \mathrm{mg} /$ gilt/day efficient is for synchronization of oestrus in gilts such that $100 \%$ express oestrus 3 to 6 days after last hormonal treatment.

In this study, pregnancy rate ranged from $45.45 \%$ to $93.33 \%$, while the mean value of farrowed piglets was between 11.6-15 piglets. Regarding the average number of weaned piglets the mean value among the groups was 8.8 to 13.14 .

\section{REFERENCES}

1. Boyer PE, Almond GW (2014). Use of altrenogest at weaning in primiparous sows, J Swine health Prod.; 22(3):134-137.

2. Coffey RD, Parker GR, Laurent KM (1997). Manipulation of the estrus Cycle in Swine, University of Kentucky College of Agriculture Cooperative Extension Service, Lexington, Kentucky, USA. Online publication ASC-152.

3. Davis DL, Killian DB, Day BN (1976). Control of estrus in gilts with compound A-35957. Journal of Animal Science, $42,1358$.

4. Davis DL, Knight WJ and Day BN (1979). Control of estrus in gilts with progestogen. Journal of Animal Science, 49, 1506-1509.

5. Dimitrov S, Bonev G, Taseva H (2010). Synchronization of estrous in gilts with Altrenogest, Agricultural Science and Technology, vol. 2, No 1, pp 3 - 5, 2010.

6. Estill CT (2000). Current concepts in oestrus synchronization in swine, J ANIM SCI 2000, 77:1-9.

7. Gerrits RJ and Johnson LA (1965). Synchronization of estrus in gilts fed two levels of I.C.I. 33.828 and the effect on fertility, embryo survival and litter size. Journal of Animal Science, Suppl. 1, 917-918, (Abstr.) 
8. KnightJW, Davis DL, Day BN (1976). Estrus synchronization in gilts with progestogen. Journal of Animal Science, 42, Suppl. 1, 1358-1359 (Abstr.).

9. Kraeling RR, Dziuk PJ, Rampacek GB, and Webel SK (1981) Synchronization of estrus in swine with allyl trebolone (RU-2267). Journal of Animal Science, 52, 831-835.
10. Polge CB, Day BN and Groves TW (1968). Synchronization of ovulation and artificial insemination in pig. Veterinary Record, 83,136-142.

11. Webel SK, Scheid JP (1980). Estrus control in pigs U.S. field trial results with a new progestin compound RU-2267Regumate. Proceeding of International Pig Veterinary Society Congress, p. 49. 